\begin{tabular}{ll}
\hline & $\begin{array}{l}\text { Kastamonu Eğitim Dergisi } \\
\text { Kastamonu Education Journal }\end{array}$ \\
$\begin{array}{l}\text { Eylül 2019 Cilt:27 Sayı:6 } \\
\text { kefdergi.kastamonu.edu.tr }\end{array}$ & Başvuru Tarihi/Received: 19.08 .2018 \\
Kabul Tarihi/Accepted: 14.02 .2019 \\
Dol: $10.24106 /$ kefdergi.3300
\end{tabular}

\title{
Öğretmenlerin Eğitsel Mobil Uygulama Geliştirme Aracı Olarak Mit App Inventor’ı Kabulü
}

\section{Teachers' Acceptance of MIT App Inventor as an Educational Mobile Application Development Tool}

\author{
Elif POLAT ${ }^{1}$, Sinan HOPCAN ${ }^{2}$
}

\section{Öz}

Bu çalışmanın amacı MIT App Inventor (AI)'ın eğitsel mobil uygulama geliştirme aracı olarak öğretmenler tarafindan kabulünü araştırmaktır. Çalışma kapsamında öğretmenlerin Al'yı kullanmalarındaki davranışsal niyetleri üzerinde algılanan yarar, algılanan kullanım kolaylığı ve algılanan eğlencenin etkileri incelenmiştir. Araştrrmada ilişkisel yöntem kullanılmıştır. Bu çalışmanın katılımcılarını devlet okullarında görev yapan, gönüllü 50 öğretmen oluşturmaktadır. Araştırma sonuçları, algılanan kullanım kolaylığı, algılanan yarar ve algılanan eğlence arasında anlamlı ilişki olduğunu göstermektedir. Ayrıca algılanan kullanım kolaylığı, algılanan yarar ve algılanan eğlencenin $\mathrm{Al}$ kullanımındaki davranışsal niyeti yordadığını, algılanan eğlencenin hem algılanan yarar hem de algılanan kullanım kolaylığının önemli bir yordayıcısı olduğunu ve algılanan kullanım kolaylığının algılanan yararın önemli bir yordayıcısı olduğunu da göstermektedir.

Anahtar Kelimeler: Teknoloji Kabul Modeli, MIT App Inventor, Öğretmen, Eğitsel Mobil Uygulama

\section{Abstract}

The purpose of this study was to investigate teachers' acceptance of MIT App Inventor (Al) as an educational mobile application development tool. The study examined effects of perceived usefulness, ease of use and perceived enjoyment on the behavioral intention of teachers using the Al. In this study, correlational research design was used. The participants of this study were 50 volunteer teachers who work in public schools. The findings of the study showed that there was a significant relationship among perceived usefulness, ease of use and perceived enjoyment. Also, perceived usefulness, ease of use and perceived enjoyment seemed to affect behavioral intention while perceived enjoyment affected both perceived usefulness and ease of use. Moreover, ease of use affected perceived usefulness.

Keywords: Technology Acceptance Model, MIT App Inventor, Teacher, Educational Mobile Application

\footnotetext{
1. İstanbul Üniversitesi-Cerrahpaşa, Hasan Ali Yücel Eğitim Fakültesi, İstanbul, Türkiye; https://orcid.org/0000-0002-6086-9002 2. İstanbul Üniversitesi-Cerrahpaşa, Hasan Ali Yücel Eğitim Fakültesi, İstanbul, Türkiye; https://orcid.org/0000-0001-8911-3463 Atff / Citation: Polat, E., \& Hopcan, S. (2019). Öğretmenlerin eğitsel mobil uygulama geliştirme aracı olarak MIT app ınventor'ı kabulü. Kastamonu Education Journal, 27(6), 2459-2466. doi:10.24106/kefdergi.3300
} 


\section{Extended Abstract}

Introduction: Recently, smartphones and tablets have become adoptable at an extraordinary pace as mobile technologies. The number of educational mobile applications developed for students at different grades are also increasing. It is important that teachers can develop educational mobile applications that may potentially facilitate learning.

However, developing an educational mobile application can be difficult for teachers who are novice programmers. Teachers may have difficulties in learning to write code with text-based programming languages. Therefore, block-based visual programming tools offer a solution to overcome these barriers.

The block-based visual programming tool, App Inventor (Al), is a mobile application development tool. $\mathrm{Al}$ is an intuitive visual programming environment that allows anyone - even children - to create fully functional applications for smartphones and tablets (MIT App Inventor, n.d.).

Most of the studies related to Al use in education have been conducted with students of different grades, and who have programming knowledge at different levels (Andujar et al., 2012; Grover \& Pea, 2013; Morelli et al., 2011; Perdikuri, 2014; Wagner, Gray, Corley, \& Wolber, 2013; Wolber, 2011). Very few studies, however, have examined Al uses by teachers from different perspectives (Hsu \& Ching, 2013; Liu et al, 2013; Mihci \& Ozdener Donmez, 2017).

These mentioned studies have examined Al uses of teachers / preservice teachers from different perspectives. However, to the best of our knowledge, there have been no studies conducted on teachers' acceptance of Al in the literature. Al may have a significant potential because teachers with little or no knowledge of programming can develop educational mobile applications in line with the needs of educational environments. In this context, the study aims to help fill the research gap on teachers' adoption of Al as an educational mobile application development tool.

Purpose: The purpose of this study is to investigate teachers' acceptance of MIT App Inventor (Al) as an educational mobile application development tool. In this way, the findings of the study may help illuminate the potential of educational mobile application development tools. The study explored two questions as follows:

1. Do perceived usefulness, perceived ease of use, and perceived enjoyment affect behavioral intentions of teachers toward using Al?

2. What is the relationship among perceived usefulness, perceived ease of use, and perceived enjoyment in acceptance of the mobile application development tool?

This study examines the relationship among perceived usefulness, ease of use, and perceived enjoyment, and also their relationships with the behavioral intention of teachers to use Al as an educational mobile application development tool. The participants of this study were 50 volunteer teachers from Information Technologies, Science, Mathematics, and Turkish Language. They work in public schools in Bakırköy and Sancaktepe districts of Istanbul.

Method: In this study, correlational research design was used. Demographic information form was applied to obtain the demographic data of the participants. In the form, questions such as age, gender, education status, and branch were asked. An acceptance questionnaire was used to measure teachers' perceptions. The questionnaire consisted of 16 items in four parts: perceived usefulness, and perceived ease of use, perceived enjoyment, and behavioral intention.

Within the scope of the study, mobile programming workshop was organized for 50 teachers who were from various branches working in public schools (Information Technologies, Science, Mathematics, and Turkish Language). The workshop was held for two days. During the first day, teachers were introduced to programming basic concepts (variables, conditions, loops...). On the second day, teachers were introduced to Al and exercises in Al were conducted. At the end of the second day, teachers' opinions were taken with the help of a questionnaire. In the acceptance questionnaire, each item is a 5-point Likert ( $1=$ strongly disagree- $5=$ strongly agree). Cronbach alpha values of reliability analysis were $.89, .94, .83$, and .91 for perceived ease of use, perceived usefulness, perceived enjoyment, and behavioral intention, respectively.

Results and Discussion: Multiple regression analyses were employed in order to investigate the relationship among the variables and their effects on the behavioral intention to use Al. The findings of the study showed that 1) there is a significant relationship among perceived usefulness, ease of use, and perceived enjoyment. 2) Perceived usefulness, ease of use, and perceived enjoyment seemed to affect behavioral intention. 3) Perceived enjoyment affected both perceived usefulness and ease of use 4) ease of use affected perceived usefulness. It is expected that the study can shed light on acceptance of $\mathrm{Al}$ as an educational mobile application development tool.

Suggestions for future studies are as follows:

- App Inventor training can be given to teachers of different grades, different branches and more. Different exercises can be added to trainings.

- In order to make teachers able to develop their own materials, number of such workshops should be increased with enriched content.

- Comparison studies can be carried out using different programs.

- A limited number of variables were included in the study. Variables such as attitude, cultural differences can be added.

| Kastamonu Eğitim Dergisi, 27(6), 2019| 


\section{Giriş}

Son yıllarda mobil teknolojiler olarak akıllı telefon ve tabletlerin olağanüstü bir hızla benimsenmeye başladığı görülmektedir. Android telefon/tablet, iPhone, iPad gibi mobil cihazlar A-12 öğrencileri ve öğretmenleri arasında giderek daha yaygın bir biçimde kullanılmaya başlamıştır (Liu ve diğerleri, 2013). Mobil uygulamalar pazarlama, sağlık, spor ve eğitim gibi pek çok alanda hayatımıza girmeyi başarmıştır.

Eğitim alanında farklı kademelerdeki öğrenciler için geliştirilen eğitsel mobil uygulamaların sayısı giderek artmaktadır. Eğitsel mobil uygulamalar günümüzde öğrencilerin öğrenmesini kolaylaşttrma potansiyeline sahiptir (Foti \& Mendez, 2014; Ling, Harnish, ve Shehab, 2014). Ancak öğretmenler dersleriyle doğrudan ilgili ve derslerindeki kazanımlara uygun mobil uygulamaları her zaman bulamamaktadır. Bu noktada, öğretmenlerin kendi kendilerine mobil uygulama geliştirmeleri önemli hale gelmektedir (Hsu ve Ching, 2013). Goundar (2011) da eğitimcilerin mobil cihazlar için öğretim materyalleri geliştirmesinin gerekli olduğunu dile getirmektedir. Bununla birlikte, eğitsel mobil uygulama geliştirmek, programlama deneyimi olmayan öğretmenler için zor olabilmektedir. Öğretmenler metin tabanlı programlama dilleriyle kod yazmayı öğrenirken güçlük yaşamaktadır. Bu güçlüklerin üstesinden gelebilmek için blok tabanlı görsel programlama araçları çözüm sunmaktadır. Sözü edilen araçlar, kullanıcıların farklı bileşenlerin parçalarını bir araya getirdikten hemen sonra neler yaptıklarını görmelerine ve kullanıcılara geliştirdikleri ürünleri test etmelerine olanak tanımaktadır (Hsu ve Ching, 2013). Alice, Scratch, Lego Mindstorms NXT ve MIT App Inventor (AI) gibi araçlar programlamaya girişte yaşanan engelleri azaltmaktadır (Roy, 2012). Şöyle ki bu araçlar, metin tabanlı kodlarda kaybolmayı ve hata ayıklamanın verdiği hayal kırıklıklarını azaltarak, kullanıcılara daha keyifli bir programlama deneyimi sağlamaktadır (Hsu ve Ching, 2013).

Blok tabanlı görsel programlama araçlarından olan Al ise bir mobil uygulama geliştirme aracıdır. Al herkese -hatta çocuklara- akıllı telefonlar ve tabletler için işlevsel uygulamalar oluşturma imkanı veren sezgisel, görsel bir programlama ortamıdır. Al programını kullanmaya yeni başlayan kişiler, ilk uygulamalarını 30 dakikadan daha kısa bir sürede geliştirebilirler. Dahası, blok tabanlı olan bu araç ile geleneksel programlama ortamlarına göre çok daha kısa bir sürede karmaşık uygulamalar geliştirilebilmektedir. Al'nın temel amacı, tüm insanlara, özellikle gençlere teknoloji tüketiminden teknoloji üretimine geçme konusunda güç vererek uygulamalar geliştirmelerini sağlamaktır (MIT App Inventor, n.d.). Al ile uygulamalar bir web tarayıcısında geliştirilir ve internet veya USB bağlantısı aracılığıyla Android tabanlı mobil cihazlara yüklenir (Morelli, Uche Lake ve Baldwin, 2015).

Eğitimde Aı kullanımıyla ilgili çalışmaların çoğunun farklı kademelerde ve farklı seviyelerde programlama bilgisine sahip öğrenciler ile yürütüldüğü görülmektedir. Örneğin; lise öğrencilerine bilgisayar biliminin temelini öğretmek (Andujar ve diğerleri, 2012); ortaokul öğrencilerine programlamanın temellerini vermek (Grover ve Pea, 2013); A-12'deki öğrencilerin komputasyonel düşünme becerilerini geliştirmek (Morelli ve diğerleri, 2011); lise öğrencilerine programlamaya giriş dersleri vermek (Perdikuri, 2014); lise öğrencilerine Android uygulamalar geliştirmeyi öğretmek (Wagner, Gray, Corley ve Wolber, 2013); üniversite öğrencilerine programlama öğretmek (Wolber, 2011) için Al kullanılmıştr. Buna karşılık, öğretmenlerle yürütülen çalışmaların sayısı oldukça azdır (Hsu ve Ching, 2013; Liu ve diğerleri, 2013; Mihci ve Ozdener, 2017).

Hsu ve Ching (2013) programcı olmayan eğitimcilere çevrimiçi bir yüksek lisans dersinde Al ile mobil uygulama tasarımı yaptırmış ve eğitimcilerin bu öğrenme sürecine yönelik deneyimleri ve algılarını ortaya koymuşlardır. 10 eğitimcinin katıldığı çalışmada eğitimcilerin çevrimiçi dersteki mobil uygulama etkinliklerini incelemek için karma yöntem işe koşulmuştur. Sonuç olarak, eğitimcilerin bu çevrimiçi dersle ilgili görüşleri olumlu olmuştur. Ayrıca eğitimciler Al'yı işlevsel ve yararlı mobil uygulamalar geliştirebilecekleri görsel programlama aracı olarak benimsemişlerdir. Bunun yanı sıra, Al'yı kullanarak benzersiz mobil uygulamalar geliştirebileceklerine inanmışlardır. Kendi tasarım çalışmalarında ve yaratıı problem çözme becerilerini geliştirmelerinde, akranları tarafindan paylaşılan kişiselleştirilmiş mobil uygulamalardan ilham aldıklarını da dile getirmişlerdir.

Liu ve diğerleri (2013) A-12 öğretmenleri için bir haftalık Al'yi konu alan bilişim eğitimi düzenlemişlerdir. Eğitim sırasında öğretmenler gelecek dönemlerde öğretecekleri dersler için mobil uygulamalar geliştirmişlerdir. Araştırma sonuçlarına göre, öğretmenlerin kendine güven seviyelerinde \%29,5'luk; bilişim teknolojileri bilgilerinde ise \%109'luk bir arţ̧̧ görülmüştür.

Mihci ve Ozdener Donmez (2017) bilişim teknolojileri öğretmeni adaylarına programlamayı öğretirken, görsel blok tabanlı programlama dili kullanımının kısa ve uzun vadede etkilerini araştırmışlardır. Çalışmada blok tabanlı programlamanın hem akademik başarı üzerinde hem de adayların mesleki görüşleri ve tercihleri üzerindeki etkisi karma yöntem kullanılarak incelenmiştir. Sonuç olarak, görsel blok tabanlı programlamanın daha önce metin tabanlı programlamada zorlanan öğrencilerin bașarısını arttırdığı ortaya çıkmıștır. Ancak, metin tabanlı programlamava alıșkın olan öğretmen 
adayları blok tabanlı programlamaya uyum sağlamada başarısızlık göstermişlerdir.

Sınırı sayıdaki bu araştırmalar öğretmen/öğretmen adaylarının Al kullanımlarını farklı yönlerden incelese de literatürde öğretmenlerin öğretim materyali geliştirme aracı olarak Al'yı benimsemeleriyle ilgili yapılan çalışmalara rastlanamamıştr. Programlama konusunda az bilgisi olan veya hiç bilgisi olmayan öğretmenlerin eğitim-öğretim ortamlarındaki intiyaçlar doğrultusunda eğitsel mobil uygulamalar geliştirmelerini sağlamada sözü edilen özelliklerinden dolayı Al'nın kayda değer bir potansiyeli olduğu düşünülmektedir. Bu bağlamda çalışmanın, öğretmenlerin Al'yı eğitsel mobil uygulama geliştirme aracı olarak benimsemesi/kabulü konusundaki araştırma boşluğunu doldurmaya yardımcı olması amaçlanmaktadır.

Bu çalışmada, Davis (1989) tarafindan geliştirilen ve teknoloji kabul modellerinin en fazla kullanılanlarından biri olan “Teknoloji Kabul Modeli” ('Technology Acceptance Model' -TAM) kullanılmıştır. Teknoloji Kabul Modeli'ne göre kullanıcıların bir teknolojiyi kabul etme durumlarını algılanan yarar ve algılanan kullanım kolaylığı belirlemektedir. Algılanan yarar kişilerin belirli bir sistemi kullanmalarının performanslarını geliştireceğine inanma dereceleri olarak tanımlanmaktadır. Algılanan kullanım kolaylığı ise kişilerin belirli bir sistemi çaba göstermeksizin kullanabileceklerine inanma dereceleridir (Davis, 1989). Bunlar davranışsal niyeti etkilemektedir. Teknoloji Kabul Modeli'ne göre, algılanan yarar ve algılanan kullanım kolaylığı kişinin bir teknolojiyi kullanma niyetini belirlemektedir (Venkatesh, 2000). Algılanan eğlence, belirli bir sistem kullanımından kaynaklanan herhangi bir performans sonucundaki zevkin yanı sıra, bu sistemi kullanma etkinliğinin kendi başına zevkli olarak algılanması olarak tanımlanmaktadır (Venkatesh, 2000). Davranışsal niyet ise kişinin gelecekte belirli bir davranışı kendi isteğiyle gerçekleştirme veya gerçekleştirmemeye karar verme derecesi olarak tanımlanmaktadır (Warshaw ve Davis, 1985). Teknoloji kabul modelini test eden pek çok deneysel çalışmada, algılanan yarar teknoloji kullanımında davranışsal niyetin sürekli olarak güçlü bir belirleyicisi olmuştur (Venkatesh ve Davis, 2000). Algılanan yarar, algılanan eğlence ve algılanan kullanım kolaylığı değişkenlerinin birbiriyle ilişiklileri ve davranışsal niyeti etkileme durumları hakkında literatürde farklı sonuçlar mevcuttur.

Bu çalışmanın amacı Al'nın eğitsel mobil uygulama geliştirme aracı olarak öğretmenler tarafindan kabulünü araştırmaktır. Bu şekilde, eğitim ortamlarında mobil uygulama geliştirme araçlarının kullanılma potansiyelini açıklamaya yardımcı olunacağı düşünülmektedir. Bu araştırmada cevap aranan sorular şu şekildedir:

1. Öğretmenlerin mobil uygulama geliştirme aracını kabulleri üzerinde etkisi araştıılan algılanan yarar, algılanan kullanım kolaylığı ve algılanan eğlence arasındaki ilişki nedir?

2. Algılanan yarar, algılanan kullanım kolaylığı ve algılanan eğlence öğretmenlerin eğitsel mobil uygulama geliştirme aracını kullanmalarına yönelik davranışsal niyetlerini etkilemekte midir?

\section{Yöntem}

Bu çalışmada ilişkisel araştırma modeli kullanılmıştır. Iliş̧isel çalışmalar, iki veya daha fazla niceliksel değişken arasındaki ilişkiyi ve bu ilişkinin derecesini belirlemek için kullanılır. ilişkiler incelenirken değişkenlere müdahale edilmez (Frankel, Wallen ve Hyun, 2012). Bu ilişkisel araştırmada algılanan yarar, algılanan kullanım kolaylığı ve algılanan eğlence arasındaki ilişkiyi araştırarak ve bu değişkenlerin davranışsal niyeti nasıl yordadığını tanımlayarak Al'nın eğitsel mobil uygulama geliştirme aracı olarak öğretmenler tarafindan kabulü incelenmektedir.

\section{Katilımcilar}

Çalışmada elverişli örnekleme tekniği kullanılmıştr. Çalışmanın katlımcılarını İstanbul'un Bakırköy ve Sancaktepe ilçelerinde yapılan eğitime katılan ve bu ilçelerde devlet okullarında görev yapan 50 Bilişim Teknolojileri, Fen Bilimleri, Matematik ve Türkçe öğretmenleri oluşturmaktadır. Öğretmenlerin 31'i kadın, 19'u erkektir. Ayrıca 38'i lisans, 12'si yüksek lisans mezunudur (Tablo 1). Öğretmenlerin 21'i 0-5 yıl; 16'sı 5-10 yıl; 7'si 10-15 yıl; kalan 6'sı da 15 yıl ve üzeri deneyimlidir (Tablo 2).

Tablo 1. Demografik bilgiler

\begin{tabular}{lccccc}
\hline & & \multicolumn{2}{c}{ Cinsiyet } & \multicolumn{2}{c}{ Eğitim Durumu } \\
\cline { 3 - 6 } Branşlar & Toplam & Erkek & Kadın & Lisans & Yüksek Lisans \\
\hline Bilişim Teknolojileri & 8 & 7 & 1 & 7 & 1 \\
Fen Bilimleri & 6 & 2 & 4 & 5 & 1 \\
Matematik & 35 & 10 & 25 & 25 & 10 \\
Türkçe & 1 & 0 & 1 & 1 & 0 \\
\hline Toplam & 50 & 19 & 31 & 38 & 12 \\
\hline
\end{tabular}

| Kastamonu Eğitim Dergisi, 27(6), 2019 | 
Tablo 2. Öğretmenlerin hizmet yılları

\begin{tabular}{|l|c|c|c|c|c|}
\hline Hizmet Yılları & $\mathbf{0 - 5}$ & $\mathbf{5 - 1 0}$ & $\mathbf{1 0 - 1 5}$ & $\mathbf{1 5 - 2 0}$ & $\mathbf{2 0 - 2 5}$ \\
\hline & 21 & 16 & 7 & 2 & 4 \\
\hline
\end{tabular}

\section{Veri Toplama Araçları}

Katılımcıların demografik verilerini saptamak için demografik bilgi formu kullanıımıştır. Formda yaş, cinsiyet, eğitim durumu, branş gibi sorular sorulmuştur. Öğretmenlerin algılarını ölçmek için kabul anketi kullanılmıştr. Anket, algılanan yarar ( 7 madde), algılanan kullanım kolaylığı (4 madde), algılanan eğlence ( 2 madde) ve davranışsal niyet (3 madde) olmak üzere dört kısımdan ve 16 maddeden oluşmaktadır. Algılanan yarar, algılanan kullanım kolaylığı ve davranışsal niyet kısımlarında Davis (1989)'in çalışmasından; algılanan eğlence kısmında Venkatesh ve Bala (2008)'dan yararlanılmıştır. Kabul anketinin Türkçe versiyonu (Tokel ve Isler, 2013) kullanılmıştır. Kabul anketinde her bir madde $5^{\prime} l i$ likert şeklindedir (1= Kesinlikle katılmıyorum-5=Kesinlikle katılıyorum). Güvenilirlik analizi sonucu Cronbach alfa değerleri algılanan kullanım kolaylığı, algılanan yarar, algılanan eğlence ve davranışsal niyet için sırasıyla $.89, .94, .83$, ve .91'dir. Sonuçlar, anketin iç tutarlıık açısından iyi bir güvenilirliğe sahip olduğunu göstermektedir (Cortina, 1993).

\section{Verilerin Toplanması}

Çalışma kapsamında devlet okullarında görev yapmakta olan çeşitli branşlardan (Bilişim Teknolojileri, Fen Bilimleri, Matematik ve Türkçe) 50 öğretmene mobil programlama eğitimi düzenlenmiştir. Eğitim ilk gün programlamaya giriş eğitimi (değişken, döngü, koşul ifadeleri vb.) ve ikinci gün uygulamalı Al eğitimi olmak üzere iki gün sürmüştür. İkinci günün sonunda öğretmenlerin görüşleri kabul anketi yardımıyla alınmıştır.

\section{Verilerin Analizi}

Veriler SPSS 21 kullanılarak analiz edilmiştir. Değişkenler arasındaki ilişkiyi ve Al'yı kullanmada davranışsal niyet üzerindeki etkilerini araştırmak için çoklu doğrusal regresyon analizi kullanılmıştır. Çoklu doğrusal regresyon analizi algılanan yarar, algılanan kullanım kolaylığı ve algılanan eğlencenin davranışsal niyeti ne ölçüde yordadığını araştırmak için kullanılmıştır. Bunun yanı sıra algılanan kullanım kolaylığı ve algılanan eğlencenin algılanan yararı yordama durumunu incelemek için de çoklu doğrusal regresyon analizi kullanılmıştır. Ayrıca beta katsayısı regresyon analizini yorumlamak için kullanılmıştır (Büyüköztürk, 2014).

\section{Bulgular}

Algılanan Yarar, Algılanan Kullanım Kolaylığı ve Algılanan Eğlence Arasındaki illişki

Algılanan yarar, algılanan kullanım kolaylığı ve algılanan eğlence arasındaki Pearson çarpım korelasyon katsayıları Tablo 3'te görülmektedir. Algılanan kullanım kolaylığı, algılanan yarar $(r=.46, p<.01)$; algılanan yarar, algılanan eğlence $(r=.84, p<.01)$; ve algılanan kullanım kolaylığı, algılanan eğlence $(r=.57, p<.01)$ arasında anlamlı ilişki vardır.

Tablo 3. Pearson korelasyon katsayıları

\begin{tabular}{|c|c|c|c|}
\hline Değişkenler & Algılanan Yarar & Algılanan Kullanım Kolaylığı & Algılanan Eğlence \\
\hline Algılanan Yarar & - & & \\
\hline $\begin{array}{l}\text { Algılanan Kullanım Kolay- } \\
\text { |ığı }\end{array}$ & $.46^{*}$ & - & \\
\hline Algılanan Eğlence & $.84^{*}$ & $.57^{*}$ & \\
\hline
\end{tabular}

Davranışsal Niyet, Algılanan Yarar ve Algılanan Kullanım Kolaylığı'nın Yordanma Durumları

Davranışsal niyeti yordayan değişkenler için çoklu doğrusal regresyon analizi özeti Tablo 4'te sunulmuştur. Sonuçlar genel regresyon modelinin anlamlı olduğunu göstermektedir $\left(R^{2}=.64, F(3,46)=26.81, p<.001\right)$. Davranışsal niyet puanlarındaki varyasyonun \% 64'ünü algılanan kullanım kolaylığı, algılanan yarar ve algılanan eğlence açıklamaktadır. Beta katsayı kareleri incelendiğinde davranışsal niyetin en iyi yordayıcısının toplam varyansın \% 59'unu açıklayan algılanan eğlence olduğu görülmektedir. Bunun yanı sıra davranışsal niyetin ikinci en iyi yordayıcısı toplam varyansın \% 36'sını açıklayan algılanan kullanım kolaylığıdır.

Tablo 4. Davranışsal niyet için çoklu doğrusal regresyon analizi özeti

\begin{tabular}{lccccc}
\hline Değişkenler & B & SE B & $\boldsymbol{\beta}$ & $\mathbf{r}_{s}$ & $\left(\mathbf{r}_{s}\right)^{2}$ \\
Algılanan Yarar & .20 & .20 & $.16^{*}$ & .69 & .47 \\
Algılanan Kullanım Kolaylığı & .29 & .12 & $.25^{*}$ & .60 & .36 \\
Algılanan Eğlence & .52 & .19 & $.49 * *$ & .77 & .59
\end{tabular}


Davranışsal niyetin yanı sıra algılanan yarar ve algılanan kullanım kolaylığı için de regresyon analizi yapılmıştr. Algılanan yararı yordayan değişkenler için çoklu doğrusal regresyon analizi özeti Tablo 5 'te sunulmuştur. Sonuçlar genel regresyon modelinin anlamlı olduğunu göstermektedir $\left(R^{2}=.70, F(2,47)=54.94, p<.001\right)$. Algılanan yarar puanlarındaki varyasyonun \% 70'ini algılanan kullanım kolaylığı ve algılanan eğlence açıklamaktadır. Beta katsayı kareleri incelendiğinde algılanan yararın en iyi yordayıcısının toplam varyansın $\% 70$ 'ini açıklayan algılanan eğlence olduğu görülmektedir.

Tablo 5. Algılanan yarar için çoklu doğrusal regresyon analizi özeti

\begin{tabular}{lccccc}
\hline Değişkenler & B & SE B & $\boldsymbol{\beta}$ & $\mathbf{r}_{\mathrm{s}}$ & $\left(\mathbf{r}_{s}\right)^{2}$ \\
\hline Algılanan Kullanım Kolaylığı & -.02 & .09 & -.02 & .46 & .21 \\
Algılanan Eğlence & .72 & .08 & $.85^{*}$ & .84 & .70 \\
\hline $\mathrm{R}^{2}=.70(\mathrm{p}<.001)$ & & & & & \\
${ }^{*} \mathrm{p}<.01$ & & & & &
\end{tabular}

Algılanan kullanım kolaylığını yordayan değişkenler için çoklu doğrusal regresyon analizi özeti Tablo 6'da sunulmuştur. Sonuçlar genel regresyon modelinin anlamlı olduğunu göstermektedir $\left(R^{2}=.32, F(2,47)=54.94, p<.001\right)$. Algılanan yarar puanlarındaki varyasyonun \% 32'sini algılanan kullanım kolaylığı ve algılanan eğlence açıklamaktadır. Beta katsayı kareleri incelendiğinde algılanan yararın en iyi yordayıcısının toplam varyansın \%32'sini açıklayan algılanan eğlence olduğu görülmektedir.

Tablo 6. Algılanan kullanım kolaylığı için çoklu doğrusal regresyon analizi özeti

\begin{tabular}{lccccc}
\hline Değişkenler & $\mathbf{B}$ & SE B & $\boldsymbol{\beta}$ & $\mathbf{r}_{\mathrm{s}}$ & $\left(\mathbf{r}_{\mathrm{s}}\right)^{\mathbf{2}}$ \\
\hline Algılanan Yarar & -.05 & .24 & -.05 & .46 &. $\mathbf{2 1}$ \\
Algılanan Eğlence & .57 & .20 & $.61^{*}$ & .57 &. $\mathbf{3 2}$ \\
\hline $\mathrm{R}^{2}=.32(\mathrm{p}<.001)$ & & & & & \\
${ }^{*} \mathrm{p}<.01$ & & & & & \\
\hline
\end{tabular}

\section{Sonuç ve Tartışma}

Bu çalışmanın amacı Al'nın eğitsel mobil uygulama geliştirme aracı olarak öğretmenler tarafindan kabulünü araştırmaktır. Çalışma kapsamında öğretmenlerin Al'yı kullanmalarındaki davranışsal niyetleri üzerinde algılanan yarar, algılanan kullanım kolaylığı ve algılanan eğlencenin etkileri incelenmiştir. Bunun yanı sıra bu değişkenler arasındaki ilişkiler de incelenmiştir. Araştırma sonuçları şu şekildedir: 1) Algılanan kullanım kolaylığı, algılanan yarar, algılanan yarar ve algılanan eğlence arasında anlamlı ilişki vardır. 2) Kullanım kolaylığı, algılanan yarar ve algılanan eğlence Aı kullanımındaki davranışsal niyeti yordamaktadır. 3) Algılanan eğlence hem algılanan yarar hem de algılanan kullanım kolaylığının önemli bir yordayııısıdır. 4) Algılanan kullanım kolaylığı algılanan yararın önemli bir yordayıcısıdır.

Araştırma sonuçları öğretmenlerin Al'yı kullanmalarındaki davranışsal niyetlerinin en iyi yordayıcısının üç faktör arasından algılanan eğlence olduğunu ortaya koymaktadır. Yani, öğretmenler Al'yı kullanırken eğlendikçe, Al'yı kullanmaya daha fazla niyetlenmektedirler.

Bu sonuca paralel olarak Moon ve Kim (2001) de algılanan eğlenceyi algılanan yarara göre daha güçlü bir yordayıCı olarak bulmuşlardır. Bu sonuçtan farklı olarak, algılanan eğlencenin algılanan yarara göre davranışsal niyeti daha az etkilediğini ortaya koyan çalışmalar mevcuttur (Davis, Bagozzi ve Warshaw, 1992; Tokel ve Isler, 2013). Bu çalışmadakine benzer şekilde Yi ve Hwang (2003) de algılanan eğlenceyi algılanan kullanım kolaylığına göre daha güçlü bir yordayıcı olarak belirtmektedirler.

Algılanan eğlencenin diğer faktörlerle ilişkisine bakıldığında, sonuçlar algılanan eğlencenin algılanan yarar ve algılanan kullanım kolaylığının en önemli yordayıcısı olduğunu göstermektedir. Yani, öğretmenler Al'nin kullanımını eğlenceli bulduysa, Al'yı materyal geliştirmek için de yararlı olarak algılamaktadırlar. Literatürdeki araştırmalarda da benzer sonuçlara ulaşılmıştır (Park, Nam ve Cha, 2012; Yi ve Hwang, 2003).

Al gibi görsel blok tabanlı araçları kullanmak metin tabanlı programlama araçlarındaki zorluk ve hata ayıklama gibi durumlar olmayacağı için daha eğlencelidir. Ayrıca Al'da geliştirilen ürün, emülatör programları sayesinde mobil cihaza bile ihtiyaç duymadan görüntülenebilmektedir. Yani öğretmenler geliştirdikleri ürünü hemen görebilmektedirler. Bu durum da Al kullanmanın eğlenceli olmasına katkıda bulunmaktadır. Yi ve Hwang (2003) da buna paralel bir sonuç ortaya koymuşlardır.

Araştırma sonuçları öğretmenlerin Al'yı kullanmalarındaki davranışsal niyetlerinin ikinci önemli yordayıcısının algı|Kastamonu Eğitim Dergisi, 27(6), 2019| 
lanan yarar olduğunu ortaya koymaktadır. Yani, öğretmenler Al'yı yararlı olarak algılıyorsa, gelecekte kullanmaya istekli olmaktadırlar. Bu çalışmanın sonucundan farklı olarak araştırmalarda davranışsal niyetin en önemli ve en güçlü yordayıcısı olarak algılanan yarar bulunmuştur (Sánchez-Prieto, Olmos-Migueláñez ve García-Peñalvo, 2017; Teo, 2009; Tokel ve Isler, 2013; Venkatesh ve Davis, 2000).

Araştırmanın diğer bir sonucu davranışsal niyeti en az etkileyen değişkenin kullanım kolaylığı olduğudur. Bu duruma Al'nın blok tabanlı, görsel ve daha önce hiç deneyimi olmayan veya az deneyimi olan kişilerin bile kolayca kullanabileceği biçimde olması sebep gösterilebilir. Chow, Herold, Choo ve Chan (2012) ve Teo (2009) algılanan kullanım kolaylığının davranışsal niyet üzerinde etkisi olduğunu ortaya koymuşlardır.

Al'nın kabulünü etkileyen faktörlerin ortaya koyulmasının önemli olduğu düşünülmektedir. Bu değişkenler ve ilişkiler konusunda farklı görüşler mevcut olsa da, araştırmanın Al'nın bir materyal geliştirme aracı olarak öğretmenler tarafindan kabulüne ilişkin önemli noktalara ışık tutması beklenmektedir. Al eğitim-öğretim ortamları için uygulama geliştirilmesinin yanı sıra öğretmenlerin eğlenmesini de sağlayabilmektedir. Bu nedenle, öğretmenler Al'nın kullanımını eğlenceli bulduysa, Al'nın yanı sıra kendi uygulamalarını geliştirecekleri benzer teknolojilere de kolaylıkla adapte olabilirler. Öğretmenler bazı programları/uygulamaları yararlı olsa da eğlenceli olmadığı için kullanmaktan kaçınabilmektedirler. Bu nedenle yöneticilerin, eğitim politikası geliştirenlerin, eğitim yetkililerinin sadece yararlı değil aynı zamanda eğlenceli uygulamaları öğretmenlere önermeleri önemlidir.

Gelecekteki çalışmalar için öneriler şu şekildedir:

- Farklı kademelerden, farklı branşlardan ve daha fazla sayıdaki öğretmenlere App Inventor eğitimi verilebilir. Eğitimlere farklı etkinlikler eklenebilir.

- Bu tür eğitimlerin sayısı artırılarak ve içeriği genişletilerek öğretmenlerin kendi materyallerini kendilerinin geliştirmeleri sağlanabilir.

- Farklı programlar kullanılarak karşılaştırma çalışmaları yürütülebilir.

- Araştırmaya sınırlı sayıda değişken dahil edilmiştir. Araştırmalara tutum, kültürel farklıklar gibi değişkenler eklenebilir.

\section{Kaynakça}

Andujar, M., Aguilera, L., Jimenez, L., Zabe, F., Shah, J., Jimenez, Y., ve Morreale, P. (2012, June). Attracting high school students to computing: A case study with drag-drop interfaces. In EdMedia: World Conference on Educational Media and Technology (pp. 525-530). Association for the Advancement of Computing in Education (AACE).

Büyüköztürk, Ş. (2014). Sosyal bilimlerde veri analizi el kitabı (18. Baskı). Pegem Akademi: Ankara.

Chow, M., Herold, D. K., Choo, T., ve Chan, K. (2012). Extending the technology acceptance model to explore the intention to use second life for enhancing healthcare education. Computers \& Education, 59, 1136-1144.

Cortina, J. M. (1993). What is coefficient alpha? An examination of theory and applications. Journal of applied psychology, 78(1), 98.

Davis, F. D. (1989). Perceived usefulness, perceived ease of use and user acceptance of information technology. MIS Quarterly, 13(3), 319-339

Davis, F. D., Bagozzi, R. P., ve Warshaw, P. R. (1992). Extrinsic and intrinsic motivation to use computers in the workplace. Journal of Applied Social Psychology, 22, 1111-1132.

Foti, M. K., ve Mendez, J. (2014). Mobile learning: how students use mobile devices to support learning. Journal of Literacy and Technology, 15(3), 58-78.

Fraenkel, J., Wallen, N., ve Hyun, H.H. (2012). How to design and evaluate research in education (8th ed.). Boston: McGraw Hill.

Goundar, S. (2011, December). What is the potential impact of using mobile devices in education. In Proceedings of SIG GlobDev Fourth Annual Workshop (Vol. 3, pp. 1-30).

Grover, S., ve Pea, R. (2013, March). Using a discourse-intensive pedagogy and android's app inventor for introducing computational concepts to middle school students. In Proceeding of the 44th ACM technical symposium on Computer science education (pp. 723-728). ACM.

Hsu, Y. C., ve Ching, Y. H. (2013). Mobile app design for teaching and learning: Educators' experiences in an online graduate course. The International Review of Research in Open and Distributed Learning, 14(4), 117-139.

Ling, C., Harnish, D., ve Shehab, R. (2014). Educational apps: using mobile applications to enhance student learning of statistical concepts. Human Factors and Ergonomics in Manufacturing \& Service Industries, 24(5), 532-543.

Liu, J., Lin, C. H., Potter, P., Hasson, E. P., Barnett, Z. D., ve Singleton, M. (2013, March). Going mobile with app inventor for android: 
a one-week computing workshop for K-12 teachers. In Proceeding of the 44th ACM technical symposium on Computer science education (pp. 433-438). ACM.

MIT App Inventor. (n.d.). 20.07.2018 tarihinde http://appinventor.mit.edu/explore/about-us.html adresinden erişilmiştir.

Mihci, C., ve Ozdener Donmez, N. (2017). Teaching GUI-programming concepts to prospective K12 teachers: MIT app inventor as an alternative to text based languages. International Journal of Research in Education and Science (IJRES), 3(2), 543-559. DOI:10.21890/ijres.327912

Moon, J. W., ve Kim, Y. G. (2001). Extending the TAM for the World-Wide-Web context. Information and Management, 38, 217230.

Morelli, R., De Lanerolle, T., Lake, P., Limardo, N., Tamotsu, E., ve Uche, C. (2011, March). Can android app inventor bring computational thinking to k-12. In Proc. 42nd ACM technical symposium on Computer science education (SIGCSE'11) (pp. 1-6).

Morelli, R., Uche, C., Lake, P., ve Baldwin, L. (2015, February). Analyzing year one of a cs principles pd project. In Proceedings of the 46th ACM technical symposium on Computer science education (pp. 368-373). ACM.

Park, S. Y., Nam, M. W., ve Cha, S. B. (2012). University students' behavioral intention to use mobile learning: Evaluating the technology acceptance model. British Journal of Educational Technology, 43(4), 592-605.

Perdikuri, K. (2014). Students' Experiences from the use of MIT App Inventor in classroom. In Proceedings of the 18th Panhellenic conference on informatics (pp. 1-6). ACM.

Roy, K. (2012). App inventor for android: report from a summer camp. In Proceedings of the 43rd ACM technical symposium on Computer Science Education (pp. 283-288). ACM.

Sánchez-Prieto, J. C., Olmos-Migueláñez, S., ve García-Peñalvo, F. J. (2017). MLearning and pre-service teachers: An assessment of the behavioral intention using an expanded TAM model. Computers in Human Behavior, 72, 644-654.

Teo, T. (2009). Modelling technology acceptance in education: A study of pre-service teachers. Computers \& Education, 52(2), 302-312.

Tokel, S. T., ve Isler, V. (2013). Acceptance of virtual worlds as learning space. Innovations in Education and Teaching International, 52(3), 254-264.

Venkatesh, V. (2000). Determinants of perceived ease of use: Integrating control, intrinsic motivation, and emotion into the technology acceptance model. Information systems research, 11(4), 342-365.

Venkatesh, V., ve Bala, H. (2008). Technology acceptance model 3 and a research agenda on interventions. Decision Sciences, 39, 273-315.

Venkatesh, V., ve Davis, F. D. (2000). A theoretical extension of the technology acceptance model: Four longitudinal field studies. Management science, 46(2), 186-204.

Wagner, A., Gray, J., Corley, J., ve Wolber, D. (2013). Using app inventor in a K-12 summer camp. In Proceeding of the 44th ACM technical symposium on Computer science education (pp. 621-626). ACM.

Warshaw, P. R., ve Davis, F. D. (1985). Disentangling behavioral intention and behavioral expectation. Journal of experimental social psychology, 21(3), 213-228.

Wolber, D. (2011). App inventor and real-world motivation. In Proceedings of the 42nd ACM technical symposium on Computer science education (pp. 601-606). ACM.

Yi, M. Y., ve Hwang, Y. (2003). Predicting the use of web-based information systems: Self-efficacy, enjoyment, learning goal orientation, and the technology acceptance model. International Journal of Human-Computer Studies, 59, 431-449. 